\title{
CORPUS-BASED TRANSLATION STUDIES: WHERE DOES IT COME FROM? WHERE IS IT GOING? ${ }^{1}$
}

Sara Laviosa*

\begin{abstract}
The idea of investigating translation and translating through corpora was first put forward by Baker in 1993. At the time it was envisaged that in this new partnership Corpus Linguistics would provide the methodology for carrying out empirical investigations while translation theory would identify the areas of enquiry and elaborate operational hypotheses. The two partners would work in harmony mainly for the benefit of the advancement of the descriptive branch of the discipline. Since then the partnership has acquired a clear identity with a specific denomination, Corpus-Based Translation Studies (CTS). Its areas of research range from descriptive to applied studies, and concern many different languages. In this paper I will examine the links existing between CTS, Corpus Linguistics and Descriptive Translation Studies (DTS) with a view to establishing which claims put forward in the past still hold true and which are the most fruitful areas of longterm CTS research. My paper is organised in three chronological sections, each corresponding to a salient moment in the history of CTS. The first two years 1993-1995 see the dawn of CTS, the period of time between 1996 and 1999 represents what I see as the corpus linguistic turn in Translation Studies, while from 2000 onwards it is plausible to envisage a cultural studies turn in CTS.
\end{abstract}

* University of Bari, Italy.

1 This is an abridged version of my keynote speech delivered at the CorpusBased Translation Studies Conference. Research and Applications, University of South Africa and University of Manchester, Pretoria, 21-25 July 2003, whose proceedings are to be published in a special issue of Language Matters (2004) edited by Alet Kruger.

TRADTERM, 10, 2004, p. 29-57 
KEYWORDS: cultural studies, universals, corpus linguistics, Descriptive Translation Studies, applied corpus-based translation studies, critical linguistics, theoretical corpusbased translation studies, descriptive corpus-based translation studies.

RESUMO: A idéia de estudar a tradução e o ato de traduzir por meio de corpora foi sugerida inicialmente por Baker, em 1993. Àquele tempo, acreditava-se que essa nova parceria com a Lingüística de Corpus forneceria a metodologia para o estudo empírico, enquanto a Teoria da Tradução se encarregaria de identificar as áreas de pesquisa e elaborar hipóteses operacionais. As duas parceiras trabalhariam em harmonia em prol do avanço da corrente descritiva da disciplina. Desde então, a parceria adquiriu uma identidade clara e com denominação específica: Corpus-Based Translation Studies - CTS (Estudos de Tradução Baseados em Corpus). Suas áreas de pesquisa variam de estudos descritivos a aplicados, e contemplam diversas línguas. Neste artigo, pretendo examinar as ligações existentes entre CTS, Lingüistica de Corpus e DTS (Descriptive Translation Studies) com o objetivo de verificar quais alegações feitas no passado ainda são verdadeiras e quais as áreas de pesquisa mais frutiferas a longo prazo em CTS. Meu artigo está organizado em três seções cronológicas, que correspondem a momentos-chave da história dos CTS. Os dois primeiros anos, 1993 a 1995, contemplam o surgimento dos CTS; o periodo compreendido entre os anos 1996 e 1999 representam o que chamo de predominio da Lingüistica de Corpus nos estudos de tradução; já de 2000 em diante, seria plausivel falar de um predominio dos Estudos Culturais nos CTS.

UNITERMOS: estudos culturais; lingüistica de corpus; universais; Estudos Descritivos da Tradução (DTS); estudos aplicados de tradução baseados em corpora; estudos descritivos de tradução baseados em corpora; estudos teóricos de tradução baseados em corpora; lingüistica critica.

TradTerm, 10, 2004, p. 29-57 


\section{The dawn of CTS}

In 1993 Mona Baker published Corpus linguistics and translation studies: implications and applications. The availability of large corpora of both original and translated text, together with the development of a corpus-driven methodology', Baker predicted, 'will enable translation scholars to uncover the nature of translated text as a mediated communicative event' (Baker, 1993: 243). Two years later in Corpora in translation studies: an overview and some suggestions for future research that original idea was further developed by suggesting specific research projects involving the design and analysis of parallel, bi/multilingual and above all monolingual comparable corpora. It was the dawn of a new partnership which was destined to develop into Corpus-Based Translation Studies (CTS), a new conceptual paradigm, one of the many which were to enliven translation research during the 1990s, a particularly vivacious decade characterised by a myriad of competing and complementary theoretical approaches and methodologies grown out of the cross-fertilisation with new fields of studies as varied as pragmatics, critical linguistics, postcolonialism, gender studies and globalisation, while the well-established areas of enquiry, that is polysystem, skopos, poststructuralism, and feminism were alive and well, as Venuti observes (2000).

The partnership was launched at a time of unprecedented growth in Corpus Linguistics. Mega corpora of English of no less than 100 million words were being compiled, such as the BNC, Cambridge Language Survey, Longman Corpus Network, Bank of English, the latter counting almost 500 million words. New corpus types were being designed, the interactive Corpus of Spoken American English, for example, allowed the simultaneous presentation of visual and auditory information in each concordance line (Chafe et al., 1991). Significant was also the fact that in 1990, there were already 16 corpora representing the languages of Europe for a total of 365 million words and the Council of Europe had begun to fund large-scale projects aimed at creating reference corpora for the languages of the Union. Many areas of study in applied linguistics were being influenced by the insights and methodology of Corpus Linguistics: lexicography first of all,

TRADTERM, 10, 2004, p. 29-57 
then educational linguistics, NLP, machine and computer-assisted translation, contrastive analysis, terminology, forensic linguistics, critical linguistics, to name just the principal ones. With such an impressive record of achievements the timing was right for predicting that Corpus Linguistics would make a triumphant entry also into Translation Studies. Of course corpora were not unknown to the discipline when Baker put forward her proposals. In 1986 Martin Gellerstam at the University of Lund had in fact already compiled the first monolingual comparable corpus of Swedish novels to study translationese and Hans Lindquist in 1989, again in Lund, had investigated the Swedish renderings of English adverbials with a parallel language data base. Their research intended to use corpora as aids to improve the practice of translation. What was being proposed in the early 90s was instead a composite programme of research within Descriptive Translation Studies which, thanks to polysystem theorists (i.e. Itamar Even-Zohar, Gideon Toury and Andrè Lefevere), had developed considerably to the point that Toury (1995) had assigned to DTS a pivotal role for the evolution of Translation Studies into a fully-fledged empirical discipline. The strong links forged in those years between Corpus Linguistics and DTS thanks to a set of common concerns stemming from an empirical perspective is, in my view, one of the keys if not the key to the success story of CTS. Let's remind ourselves what these shared issues are. Both fields of enquiry investigate authentic samples of language use rather than idealised or intuitive language data; linguistic regularities are regarded as probabilistic norms of behaviour rather than prescriptive rules; moreover, these language patterns are inextricably related to socio-cultural variables in as far as they reflect and reproduce culture. Both CL and DTS adopt a comparative research model in which descriptive hypotheses that make claims about the probabilistic generality of a given phenomenon are put forward and texts are examined across corpora representing different language varieties, for example translated versus non-translated language, original texts and their translations, different text types or different modalities within the same language, and so on. So the same empirical paradigm embraces the target-text oriented historical-descriptive approach developed

TRADTERM, 10, 2004, p. 29-57 
by Toury from Polysystem Theory and the corpus linguistic-descriptive approach put forward by Baker. Furthermore, corpus linguistic analytical procedures together with corpus design principles were largely compatible with Toury's 'discovery procedures' involving a gradual inductive progression from observable translational phenomena to the non-observable norms that govern translators' choices. In the mid-90s, the methodologies foreseen by Toury for DTS and by Baker for CTS were at the stage of being developed and tested. They both stressed the importance of developing a coherent descriptive methodology in order to be able to compare results, replicate studies, and systematically widen the scope of our current knowledge concerning the nature of translation. We are now going to see how CTS elaborated in practice its methodology for the advancement of DTS.

\section{The Corpus Linguistic turn in Translation Studies}

\section{Descriptive CTS}

In 1996 the first CTS analysis was carried out at UMIST, Manchester. As part of that study I created a multi-source-language monolingual comparable corpus of English and offered a synthesis between a corpus-based methodology and the investigation of simplification, a line of research pursued within DTS in the 1980s. My findings revealed core patterns of lexical use in narrative prose and newspaper articles, which were largely independent of the influence of the source language and could be regarded as aspects of simplification in translational English. Some of the methodological limitations presented by previous studies were addressed, namely the use of small text samples and lack of control for either text category or source language (Laviosa-Braithwaite, 1996). Almost at the same time and right up to the end of the decade other novel syntheses were proposed. In 1997 Jeremy Munday combined systemic functional linguistics, corpora, cultural studies and reception theory to analyse translation norms in a parallel corpus of Spanish short stories by Gabriel García Márquez and their English translations. The

TradTerm, 10, 2004, p. 29-57 
findings obtained from comparative analyses of target and source texts vis-à-vis English and Spanish reference corpora suggested that the initial norm characterising the translator's choices was oriented towards acceptability (Munday, 1997). Later on, the exploration of the third code, a notion put forward by Frawley in 1984, inspired two studies of normalisation in English and German literary translations respectively. The first is Nelia Scott's analysis (1998) of the novel A hora da estrela by Clarice Lispector and the translation carried out by the late Giovanni Pontiero, The hour of the star. The second study, realised by Dorothy Kenny (1999), examined lexical norms and creativity in a two million word parallel corpus of contemporary experimental German literary texts and their English translations (GEPCOLT). Scott looked in particular at how the repetition of the negative type não had been translated and discovered two kinds of normalisation, one linked to the systemic differences between source and target language, the other resulting from the translator's stylistic preferences. In the overall picture emerging from Kenny's study, normalisation appears to be a trend in translations of highly idiosyncratic lexical use. However, this result does not obscure the equally important finding of a non-negligible proportion of creative renderings of unusual collocations. The co-occurrence of regularities and instances of counter-examples to prevailing patterns in the investigation of universals is also a feature of my study, where simplification was by no means uniform in all text types represented in the English Comparable Corpus or for all the parameters considered. This is also the case with 'Øverås' (1998) research which tested Blum-Kulka's explicitation hypothesis (1986) in literary translations taken from the English Norwegian Parallel Corpus (ENPC). Her interpretive hypothesis was that a rise in the level of cohesion is an aspect of explicitation in the process of translation; the descriptive hypothesis was that English and Norwegian target texts are more cohesive than their source texts. Both predictions were largely confirmed since the explicitating shifts outnumbered the implicitation strategies. In addition to the constraints inherent in the mediating process of translation, a variety of factors were hypothesised as good candidates for explaining explicitation in follow-up studies, for example

TRADTERM, 10, 2004, p. 29-57 
the stylistic preferences of source and target language, their systemic differences as well as culture-bound translation norms, which, as Rachel Weissbrod pointed out (1992), are amenable to change with historical circumstances and according to the relative position of translation in different literary systems. Moreover, explicitation was found to be associated with the tendency to prefer typical rather than unusual collocations which suggests that the universals of translation may present distinctive features but may also overlap with one another to some extent.

It seems that for every question answered many more were being thrown up, as if each study opened a sort of Pandora's Box (as conceived by Karin Littau, 1995) giving rise to a serendipity process of continual quest and discovery. The question that comes to my mind at this point is: how shall we unravel the intricate maze of what is norm-dependent and what is universal, what is specific and what is general, what is central and what is peripheral, what is divergent and what is convergent? Shall we follow Toury's lead (1980) and aim to uncover universal laws through the gradual refinement of compatible methods of enquiry, theoretical speculation and the accumulation of data yielded by studies relating to different languages, socio-cultural milieus, and periods of history? Or shall we go along with Tymoczko's view that 'the primary purpose of CTS is neither to be objective nor to uncover universal laws' but to build 'many different corpora for specialized, multifarious purposes, making room for the interests, inquiries and perspectives of a diverse world' (Tymoczko 1998: 656)? Perhaps this is a false dilemma after all since the two positions are in all probability much less apart than they appear to be if we examine them in greater depth. I think that if one regards the notion of universal not as an absolute necessity which can explain translation strategies in every single circumstance, but one considers it a descriptive construct, an openended working hypothesis, it will continue to unveil, as it has already done, more and more aspects of the nature of translation products and processes and their complex relationships with culture. The universal laws of translational behaviour put forward by Toury (1995) represent probabilistic relationships between various translational phenomena. These relationships are

TradTerm, 10, 2004, p. 29-57 
neither fixed nor absolute but are believed to be affected by a myriad of linguistic and cultural variables operating to a lesser or greater extent (or even not at all) in different conditions, i.e. historical, sociological, ideological, political, cognitive, physical, psychological. As an illustrative example of how a probabilistic principle works, I will draw a parallel between the idiom principle' posited by John Sinclair (1991) as the norm in the organisation and interpretation of language use and Toury's (1995) 'law of growing standardisation' which governs translational behaviour. According to the idiom principle words are selected in chunks (or co-selected) on the basis of their lexical attraction to one another, which determines their collocational patterns. Coselected words form semi-preconstructed phrases in which they lose all or some of their semantic force. The idiom principle is not absolute, it co-exists, with different degrees of probability, with the opposite 'open-choice principle', whereby words are selected in order to 'fill in a slot' which could alternatively be filled in by another word of the same class, with the same meaning and syntax. While the idiom principle is the norm in general language use enjoying a high level of probability, the open-choice principle is the exception, that is, it operates in specific text types, for example highly creative texts or specialised texts or when the language user deliberately alters the expected patterns of words and introduces what Sinclair calls 'switch points' to achieve special effects such as irony, humour, contrast, emphasis, empathy.

According to Toury's law of growing standardisation the special textual relations created in the source text, such as creative collocations, are often replaced by conventional relations in the target text (such as habitual or typical collocations) leading to the dissolution of the original set of textual relations. This is precisely what Nelia Scott found in the translation of $A$ hora da estrela, where the translator's choices, conscious or not, obligatory or optional, caused the breaking up of the cumulative effect of the author's idiosyncratic repetition of the word não with the resulting fading of the sense of void evoked in the source text. If we integrate Sinclair's and Toury's notions, the law of growing standardisation will hypothesise that the opera-

TRADTERM, 10, 2004, p. 29-57 
tion of the open-choice principle in the source text is often replaced by the default idiom principle in the target text. Again this is not an absolute law, its operation is influenced by factors such as age, extent of bilingualism, the knowledge and experience of the translator as well as the status of translation within the target culture, so that, for example, the more peripheral the status of translation, the more it will accommodate itself to established models and repertoires in the target language. With the hindsight of Kenny's findings we can hypothesise that text type is also an important factor in the operation of the law of growing standardisation in translation just as it is for the operation of the idiom principle in original texts. Her corpus was in fact designed so as to include only contemporary experimental fiction; a different design may have generated a different proportion of creative collocations.

Just as in CL the idiom and the open-choice principles are working hypotheses that are being tested systematically, so in DTS is the law of growing standardisation together with its shoal of diverse conditions. Systematic diachronic and synchronic research which is methodologically and theoretically sound can, I believe, gradually unravel the intricate network of relationships that underlie the specificity and regularities, the diversity and uniformity of translational phenomena across languages and cultures. The descriptive CTS studies examined so far aimed to play a part in this wide ranging and long term research plan by drawing on the insights of previous studies and moving forward with small scale endeavours that have the potential to be followed-up and extended. Therefore their significance lies largely on the fact that they built upon, refined and diversified the work of descriptive scholars: Blum-Kulka and Levenston (1983), Klaudy (1996; 1998), Shlesinger (1989; 1991; 1995), Toury (1985; 1991), Vanderauwera (1985). They were able to do so thanks to the development of a coherent, rigorous methodology, clear, explicit descriptive and interpretive hypotheses, and a consistent comparative research model applied to the study of the relative autonomy of translated text. Consistent with Baker's predictions, CTS contributed to bringing forward the state of the art in DTS through the study of universals.

TradTerm, 10, 2004, p. 29-57 


\section{Theoretical CTS}

At the level of theory Baker continued to be at the forefront of lively debates. From 1996 to 1999 she wrote three articles which had an influential role in strengthening the theoretical links between CTS and target-oriented approaches. She gave guidelines on how to refine hypotheses and methodology so as to render operational and verifiable abstract concepts such as the notion of universals. Moreover, the search for the patterns that identify translation qua translation, argued Baker, should go hand in hand with the assessment of the relative status of source and target languages, i.e. prestigious versus less prestigious ones. Moreover, given that translated texts are distinctive communicative events, shaped by their own goals, pressures and contexts of production, descriptive scholars need to focus on the interplay of three elements: readership expectations, theoretical pronouncements and professional practice. These can be studied by complementing textual analyses with the investigation of extra-linguistic sources of data such as historical information, book reviews, interviews with authors and translators, trends revealed by the output of publishing companies and the decisions taken by funding bodies. The inclusion of facts to be gathered outside the corpus itself constitutes an important difference between DTS and CTS on the one hand and CL on the other since for the latter, especially if one considers John Sinclair's position, the corpus is the only legitimate object of study, the only repository of relevant denotative, connotative, pragmatic and ideological meanings. But for Descriptive Translation Studies you have to look also elsewhere to enrich and explain the findings of linguistic descriptions, you can't overlook, for instance, the importance of psycholinguistic research models such as Think Aloud Protocols or the study of the interim strategies adopted by the translator as revealed by manuscripts, typescripts or corrected proofs. So long as they are rigorous and conceived from within the discipline, DTS contemplates a variety of methodologies (Toury, 1995), and so does CTS.

Still from a theoretical stance other novel syntheses were being proposed: Sandra Halverson (1998) adopted prototypical

TRADTERM, 10, 2004, p. 29-57 
categories for defining the object of study in corpus-based investigations and resolve the impasse created by the contradicting statements whereby on the one hand the legitimate data for empirical and theoretical research consists of any translation that is 'presented or regarded as such within the target culture, on whatever grounds' (Toury, 1985: 20) and on the other, professional translations enjoy a higher status, mainly on the basis of evidence from psycholinguistic studies. She suggested that the target parent population of translated works be regarded as a prototype category whose centre is taken up, but only for cultures of industrialised Western countries, by professional translations, whereas in the periphery there are clusters of different types of translation, for example those carried out by translator trainees, or those performed into the foreign language. This means that a corpus intended to be representative of the population of translated texts will consist of an array of subcorpora presenting differing degrees of relevance but all being regarded as legitimate objects of investigation. As prototypes are culture-bound, so too are the corpora designed to represent a given parent population. This raises the thorny issue of the comparability of the object of study and the consequent generalisation of individual research findings. It is a recurrent problem in CTS. In a country like Brazil, for example, where about $90 \%$ of all published literature is translated literature, it would be problematic to design a representative and balanced monolingual comparable corpus of narrative texts using the same criteria adopted for the creation of the English Comparable Corpus (Magalhães, 2001). In less common languages this difficulty is not restricted to literary genres but concerns general language use too. Many non-literary text types in Irish Gaelic, for instance, are translations, mainly from English, Kenny points out (1998). The influence of translation policies has affected the design of the Corpus of Translated Finnish (CTF) compiled at the Savonlinna School of Translation Studies under the direction of Anna Mauranen. Academic texts in the natural sciences have been excluded since this text category is not translated into Finnish. The problem interests also bi-directional parallel corpora. In designing the ENPC (English-Norwegian Parallel Corpus) the choice of texts was limited by the fact

TradTerm, 10, 2004, p. 29-57 
that many text types had been translated into Norwegian, but significantly fewer ones into English (Johansson and Hofland, 1994; Johansson, 1998). This type of imbalance has also affected CEXI, a bi-directional parallel English-Italian corpus compiled under the direction of Guy Aston at the University of Bologna in Forli. The problem, which is explained in detail by Federico Zanettin (2002), arises from the very different composition of the English and Italian parent populations of translated narrative and non-fiction works, which affects the representativeness of the original subcorpora and the level of comparability that can be achieved for the translational and the original components of the corpus as a whole. This, in turn, limits the type of comparative analyses that can be carried out. There is, in other words, a trade-off between balance and comparability on the one hand and representativeness on the other. The difficulty is going to be solved by means of a compromise: balance will be achieved in the core corpus, while representativeness will be achieved by flanking the core corpus with unidirectional parallel subcorpora which will better mirror the composition of the translation parent populations. So internal balance, representativeness and comparability can be obtained to a reasonable extent in corpus design with a bit of manoeuvring between what is 'given' and what is 'taken' as object of study in a particular socio-cultural environment. Comparability across cultures is a much more complicated matter of course, but one can at least achieve a consensus on the design principles and make them explicit so that different research communities will be able to mutually understand the rationale for particular decisions and the implications of each other's findings.

\section{Applied CTS}

Applied CTS took off slightly later compared with descriptive studies; then it grew fairly rapidly. Its beginning can be traced back to Gellerstam in 1986 and Lindquist in 1989 as I said earlier, but it is really from 1998 onwards that we can really talk of applied CTS. This new subfield of research concerning the prac-

TRADTERM, 10, 2004, p. 29-57 
tice and training of translators forged strong links with the adjacent disciplines of Contrastive Analysis, LSP, terminology, lexicography and computational linguistics. Its relationship with the theory and description of corpus studies is different from the one envisaged by Toury, who considers the applied concerns of translation teaching, translation criticism and translational aids as 'extensions' of the discipline. In contrast, the relationship between applied and pure CTS is one of interdependence. Research motivated by problems arising in the classroom or in professional translating is carried out with methods of enquiry which are very often not different from those employed in descriptive CTS. Description and applications go largely hand in hand. Sometimes experimental methods complement corpus-based and corpusdriven research (Bowker, 1998); however, at the core of applied CTS are the design and navigation of corpora created not only as sources for the retrieval of translation equivalents or as aids for improving the quality and efficiency of the final translation product, but as repositories of data used to better understand translation processes and language behaviour, from a monolingual and a contrastive perspective.

I think the work of Gavioli $(1997 ; 1999)$ and Zanettin (1998) provides a good example of the blurring of boundaries between descriptive analysis and the search for translational solutions, an important aspect of the interrelationship between the applied and descriptive subfields of CTS. Gavioli and Zanettin (1997) carried out a study where translator trainees designed, compiled and analysed a comparable Italian-English corpus of medical research articles in order to acquire a) content knowledge about a specific subject field (i.e. Hepatitis $\mathrm{C}$ disease), b) textual knowledge concerning the overall structure of medical research articles, and c) linguistic knowledge about the typical use of specialised terms (e.g. acronyms, names of tests or viruses) and words in specialised contexts, such as contrastive markers, modal verbs and tentative verbs. The analytical tools were frequency lists and KWIC concordance lines through which the selected lexical items were investigated from a semantic, syntactic, collocational and functional point of view in order to improve the understanding of medical terms that are obscure to non-expert readers and to iden-

TradTerm, 10, 2004, p. 29-57 
tify the most accurate equivalents at the level of lexis and discourse units. Similar techniques were used by Lynne Bowker (1998) in an experimental study which tested the effectiveness of using a target language monolingual corpus of specialised texts as an aid to improve subject field understanding and correct term choice and fluency.

So, at the end of the 1990s the overall picture looks like this: within the empirical paradigm whose development in the early 1990s can be regarded in line with Chesterman (1998) as the most important trend that characterises Translation Studies, a number of novel syntheses in the pure and applied branch of the discipline were being proposed and realised thanks to the development of corpus linguistic methodologies. On the whole they were received with interest by the scholarly community. Here are some notable comments expressed towards the new trend: Maria Tymoczko, (1998) regards CTS as 'central to the way that Translation Studies as a discipline will remain vital and move forward' with the proviso that meticulous descriptions of translations and translation processes in the search for linguistic norms did not overlook the characteristics of translation as cultural interface at different times and places and under different cultural conditions'. Basil Hatim (1999) also praises CTS when he claims that 'Corpus-Based Translation Studies is a truly new wave of research' providing it did not limit itself to studying only what is 'in' translated text but also what is 'of' translation, that is its ideological impact.

There was one proposal however which did not fare that well. In 1996 Mona Baker argued that the theoretical and methodological differences between the empirical paradigm informing modern linguistics and non-essentialism informing postmodern cultural studies were not irreconcilable. At that time the meeting between cultural and translation studies was giving rise to what Susan Bassnett (1998) called 'the translation turn in cultural studies'. It had followed the 'cultural turn' of the late 1980s, which had interested not only Translation Studies through the development of Polysystem Theory but also linguistics, where 'research in lexicography, corpus linguistics and frame analysis', observes Susan Bassnett, 'demonstrate the importance of context and re-

TRADTERM, 10, 2004, p. 29-57 
flects a broader cultural approach than the old-style contrastive linguistics of the past' (Bassnett, 1998, reproduced in 2001 in Athanor XII (4): 159). But although it was by now widely recognised that cultural and ideological issues were not being ignored by modern linguistic approaches, and there were already excellent examples of empirical studies which harmonised political awareness, linguistic analysis and historical research (Annie Brisset, 1990/1996; Rachel May, 1994; Hatim and Mason, 1990; 1997), Baker's invitation to consider essentialism and non-essentialism as complementary rather than opposing paradigms, was sharply criticised by some exponents of the cultural studies perspective. Pylar Godayol, for example, devoted the first chapter of Espais de frontera génere i traducció $(2000 / 2002)$ to outline the essential differences between linguistics and cultural studies and reject Baker's arguments on the basis of what she regards intrinsic rather than constructed discrepancies. It follows that attempting to overcome diversity would, in her view, not only be theoretically inconceivable but also deleterious since it would lead to a hegemonic process of gradual assimilation of one paradigm into another. I would argue that Baker's perception of the danger of a fracture within the discipline did not arise from her rejection of a plurality of voices and approaches but by a well founded preoccupation with the existence of lacerating divisions. Moreover, the possibility of integrating modern linguistics with cultural studies had not been contemplated in order to homologate differences into a polyvalent monad but to promote and encourage lively, fruitful discussions and exchanges.

So the idea of crossing the frontiers of neopositivistic empiricism to venture into the realm of non-essentialism was, at the end of the 1990s still beyond reach. The real asset was indeed the birth of a new partnership - Translation Studies and Corpus Linguistics -, which was going from strength to strength and was assuming the configuration of a paradigm within a paradigm with distinctive theoretical, descriptive and applied branches. CTS was no longer a desideratum, or a research programme, it was a reality, and it was here to stay and become a driving force in the discipline for years to come. At the end of this initial period of intense scholarly work, we can identify in line with Maria

TradTerm, 10, 2004, p. 29-57 
Tymoczko (1998) three main areas of development for the start of the new millennium as follows: first of all, the search for common ground between linguistics and the rapidly developing interdisciplinary field of cultural studies; secondly, the investigation of ideology as a factor indissolubly intertwined with the product and process of translation; and finally, to keep pace with the development of modern technologies in order to continually update, refine and diversify the methodologies adopted in descriptive and applied studies.

\section{The Cultural Studies turn in CTS}

We can share Lawrence Venuti's perception that at the start of the new millennium Translation Studies is an international network of scholarly communities who construct research and debate across conceptual and disciplinary divisions'(Venuti 2000: 334). This insight is accurate and consistent with the intention expressed in the same year by Mona Baker, Theo Hermans and Maeve Olohan to open and focus the scholarly debate on three important issues: a) comparing and contrasting the variety of research models elaborated by the different approaches and theories of translation, b) their relationship with existing paradigms, and c) the extent to which they can be applied across the wide range of phenomena considered to be legitimate data for the discipline. These were the main themes of the first international conference devoted to Research Models in Translation Studies in April 2000. It brought to light not only the spread of methods of testing or developing theories or producing or exploring new data but the conference also revealed some important developments which were taking place in CTS and played an important part in the debate during the conference and beyond.

Let's consider to what extent these developments are in line with the recommendations of Maria Tymoczko, who, two years earlier, had also praised the potential of CTS 'to illuminate both similarity and difference and to investigate in a manageable form the particulars of language-specific phenomena of many differ-

ent languages and cultures' (Tymoczko 1998: 657). Let's first

TRADTERM, 10, 2004, p. 29-57 
examine all descriptive CTS, which has grown considerably thanks to the creation of new corpora and the expansion of existing ones. The multi-source-language Corpus of Translated Finnish (CTF) and a comparable corpus of original Finnish texts have been the main sources of data for two new studies of universals. One is the investigation of the 'Unique Items Hypothesis (UIH)' put forward by Sonia Tirkkonen-Condit (2000), which predicts that the forms and functions which do not have direct equivalents in the source languages and therefore are unique to the target language, occur less frequently in the translational variety because they do not suggest themselves as first choices for the translator. The second study is Mauranen's (2000) investigation of metalanguage in translational and non-translational Finnish academic prose and in popular non-fiction. Mauranen combined two hypotheses drawn from different perspectives: Toury's law of interference and Robinson's claim (1997) that translations from a highly prestigious into a less prestigious culture which are aimed at a popular readership tend to be written in a fluent style. We will recall that, according to Toury, the degree of tolerance towards interference is affected not only by text genre but also by the relationship of dominance and prestige underlying two language communities. So, Mauranen puts forward two specific hypotheses, the first is that as a result of the law of interference Finnish academic texts translated from English will show vis-à-vis original Finnish texts a higher frequency of lexical items with the function of indicating the organisation of the text, providing comments and guiding the reader. The second hypothesis is that the effect of the law of interference is less noticeable in popular nonfiction. Both hypotheses were confirmed. In the same study Mauranen found further confirmation of the Unique Items Hypothesis when she discovered that one particular lexical item which had no equivalent in English was under-represented in translational Finnish.

From Finland to the UK the quest for universals still goes on, despite ongoing debate on the tenability of universals as a valid concept for describing and explaining the specificity of translational language. Olohan and Baker (2000) tested the explicitation hypothesis at the level of syntax through the analysis of the oc-

TradTerm, 10, 2004, p. 29-57 
currences of the reporting that in translational and original English using the Translational English Corpus (TEC) vis-à-vis a comparable corpus selected from the British National Corpus (BNC). The findings show a preference for the use of that with the verbs say and tell in translated English. This is consistent with a previous study by Burnett (1999), who found a relatively higher frequency of the optional that with another set of verbs (i.e. suggest, admit, claim, think, believe, hope and know). Lugris (2001: 282) redefined Blum-Kulka's (1986) explicitation hypothesis as 'a tendency of communicative processes' rather than a constant feature of translation qua translation, in the light of his study of TECTRA (Textos para Estilística Comparada e Traducción), an English-Galician parallel corpus of literary texts.

Whereas we can say that from 1996 to 1999 the investigation of universals was at the core of descriptive CTS, in more recent years the trend has shifted towards a greater variety of studies. Here are some examples: Baker (2000) examined the style of two literary translators represented in TEC, - Peter Bush and Peter Clark - where style comprises the translator's choices regarding the type of works to translate, the consistent use of specific strategies, as well as the use of prefaces or afterwords, footnotes or glossaries. With this investigation Baker proposed a framework within which the linguistic choices made by the translator are linked to extra-linguistic aspects of the process of translation such as the relative status of source and target language, the distance between source and target culture, the translator's choices regarding themes and literary genres and the professional status of the translator. Drawing on Douglas Biber's (1988) approach to spoken and written register variation, Kruger (2000) examined a cluster of twelve co-occurring linguistic features indicative of 'involved production' in a diachronic parallel corpus including three Afrikaans translations of The merchant of Venice. The study revealed a tendency towards a more oral, more involved and more situated style in recent (i.e. Portgieter, 1991) versus older translations (i.e. Malherbe, 1949). Camargo (2001) compiled a parallel English-Portuguese corpus representing legal, corporate and technical texts to investigate the prevailing translation strategies. Her work represents the first step towards

TRADTERM, 10, 2004, p. 29-57 
assessing the norms governing the patterning of translational behaviour in non-literary works within a given socio-cultural milieu. Similarly Lugris (2001) looked at the initial norm of acceptability versus adequacy which appeared to guide the work of literary translators when rendering contemporary English literature into Galician.

Ideology is another emerging theme in descriptive CTS. It is giving rise to corpus-based critical translation studies, an area of research which draws on the methodological and theoretical insights of corpus-based critical linguistics and complements text linguistic studies of ideology in translation. Two studies are worth mentioning. One is my investigation of the representation of Europe in translated and original English newspaper articles through the analysis of the collocational patterning of a set of keywords relating to Europe (i.e. Europe, European, European Union, EU and Union) (Laviosa, 2002). The aim is to unveil, in the context of political discourse and in one text genre, how an aspect of the British cultural identity is expressed in original and translated English. The other study is Kemppanen's (2000, 2001) research in progress into the monolingual Comparable Corpus of History Texts, which consists of Finnish original and translated history works from Russian. Most of the corpus works were published in the 1970s, when the Marxist-oriented approach to the scholarly study of Finnish history was highly valued in a political climate which favoured and encouraged Finnish-Soviet relations. Kemppanen's preliminary findings consist of a total of 50 keywords divided into lexical and grammatical words. In turn, the lexical items form two semantic fields: friendship and co-operation and class consciousness. The word ystävyys (friendship) in particular displayed a highly positive semantic prosody in translated texts versus a negative one in original works. Moreover, in translation, friendship was portrayed as an aim to be achieved by Finland and the Soviet Union working in harmony, whilst in original Finnish, the Soviet Union is portrayed as an opponent.

At the interface between descriptive and applied CTS we find new studies of translation equivalents or non-equivalents as the case may be. These are based on bilingual English-Italian

TRADTERM, 10, 2004, p. 29-57 
specialised comparable corpora. One example is my investigation of the anglicism 'business' in the COMIC-SALCA corpus of business Italian and English (Laviosa, 2003, forthcoming), while Tognini-Bonelli and Manca (2003b, forthcoming) have studied an English-Italian comparable corpus of farmhouse holidays and discussed the problem of equivalence for the collocation pairs 'welcome children', 'welcome pets' and 'welcome guests', which are associated with different semantic preferences reflecting cultural differences in the language of tourism. Stewart's (2000) classroom-based research on the use of the BNC for translating tourist brochures from Italian into English as a foreign language complements this study and shows how translator trainees working out of their mother tongue can produce natural sounding collocations through the analysis of assumed target language equivalents of high frequency source language noun groups.

In applied CTS the traditional areas of research are strengthening the established links with related disciplines and new applications are being explored. Evaluation, for instance, arguably one of the most problematic areas of translation, has been tackled by Lynne Bowker (2000), who has designed an Evaluation Corpus as a resource available to translator trainers to facilitate access to the conceptual and linguistic information of a specialised subject field to verify or correct the students' solutions and provide them with less subjective feedback based on corpus data. Tested under experimental conditions, the Evaluation Corpus has proved to be an invaluable tool for raising the level of objectivity of translation evaluation in terms of number of errors identified and corrected, quality of comments provided by the evaluator, consistency in the identification of lexical errors among evaluators, and usefulness of the evaluator's comments for editing the translation draft.

Theory, description, and applications appear to be even more interrelated than in earlier years, where there was a relatively clearer division of labour. Theory tended to be programmatic, description provided empirical data, while applied studies were informed by problems arising in the training setting. Now, however, with the availability of a variety of resources and the refinement of the methodology, description and theory are more and

TRADTERM, 10, 2004, p. 29-57 
more being combined in individual studies, and so are descriptive and applied investigations.

Before moving on to predicting what the future holds for CTS, I would like to go back to the areas of development identified at the end of the 1996-1999 period. We can say that there has been indeed a growing interest in the study of ideology, the potential of CTS for unveiling the convergent and the divergent from a linguistic and cultural point of view is being realised, CTS is keeping pace with modern technologies applying them effectively to pure research and training. But how much progress has really been made towards bridging the timely gap between linguistics and cultural studies? This too was one of the pursuits of CTS; however, the present assessment of the state of the art leads me to establish that, to date, this aim is still a desideratum, and a possible cultural studies turn in CTS is still a long way away. There are, nevertheless, tangible signs that this may become one of the most fruitful and groundbreaking venues of enquiry in the near future. What makes me say this is the concomitant development presently taking place in translation theory, empirical studies, and methodology. If we consider that more and more diversified resources are continually being created all over the world ranging from large reference corpora to small, handpicked specialised corpora, from synchronic to diachronic repositories of linguistic data, from monodirectional to bidirectional parallel corpora, and from monolingual to multilingual comparable resources, it becomes plausible to conceive and carry out interdisciplinary work that harmonises history with critical linguistics and socio-cultural and literary investigations.

Just two examples will illustrate the potential of CTS for achieving this objective. The Multilingual Corpus of Sworn Translations (MCST), which is being compiled at the University of São Paulo, Brazil, is a recent addition to COMET, a multilingual corpus for teaching and translation. The MCST will initially consist of sworn translations into Portuguese and out of English, German and Spanish, as well as translations out of Portuguese into these foreign languages. It covers a 30-year period (1972-2002), selected from the complete works of sworn translators in the state of São Paulo over a period of one hundred years (1902-2002).

TradTerm, 10, 2004, p. 29-57 
The corpus compilers envisage that this material will not only inform research into contrastive stylistics, lexicography, legal terminology, but also historical studies, in particular Brazil's immigration waves as well as the significant socio-political changes that have characterised the history of the country, with particular reference to the process of democratization following a long period of military rule which culminated in the 1988 Federal Constitution, the burgeoning industrialization of the country from the mid-1950s onwards, the opening of Brazilian economy in the 1990 s, and the strengthening of commercial and cultural exchanges (Aluísio et al., 2003; Aubert et al., 2003; Tagnin, 2003).

Another long-term project of note which draws on CTS, cultural and literary studies is entitled Dante's modern after life. It is currently directed by Annamaria Sportelli at the University of Bari. It will involve the creation of a diachronic parallel ItalianEnglish corpus of Dante's Purgatory and Hell with a view to conducting a study of the shifts and adaptations characterising the English renderings of Dante's works in the translations by Henry Francis Carey in 1844, Henry Longfellow in 1895, Dorothy L. Sayers in 1949 and Allen Mandelbaum in 1980.

At the level of translation theory the general trend seems to be favourable to starting a dialogue between postmodern cultural studies and textual theories on the one hand, and empirical descriptive studies on the other. I'm referring here in particular to the set of 30 'theses' which were identified at the beginning of 2000 by Andrew Chesterman and Rosemary Arrojo (2000) as representing the shared ground between essentialism and nonessentialism on three main issues in Translation Studies, namely the definition, nature and effects of its object of study. There is of course a link between these endeavours to engage in constructive exchanges of views and perspectives and Baker's (2002) past and recent recommendations to corpus builders and analysts to document and study the extra-linguistic factors that come into play when texts are produced so as to go beyond the text as a formal structure and explore the relationship between linguistic patterns and text users.

It therefore seems neither unreasonable nor too far-fetched to envisage that what the future holds for Corpus-Based Trans-

TRADTERM, 10, 2004, p. 29-57 
lation Studies is the promotion of rich, varied, interdisciplinary work within its own areas of enquiry and beyond them, leading the way towards greater unity, fully respecting the diversity of each perspective involved. If I may draw on Edward Said's (1991) metaphors representing scholarly attitudes, that is, the academic potentate on one side of the border and the academic travellers on the other, I would say that bringing about what I would like to see as a true and long-lasting cultural studies turn in CTS will neither expand the sovereignty of linguistics nor stifle the wandering nature of the migrant experience in Translation Studies. The way I wish to foster the cultural studies turn in CTS is rather through the metaphor of pioneers inspired by endless intellectual curiosity as well as the willingness to encourage cultural exchange and open up their frontiers to friendly neighbours.

\section{References}

ALUÍSIO, S.M; PINHEIRO, G.M.; FINGER, M.; das GRAÇAS, M.; NUNES, V. and TAGNIN, S.E.O. (2003) The Brazilian Portuguese corpus LacioWeb: overview and issues in corpus creation. In: Archer, D.; Rayson, P.; Wilson, A. and McEnery, T. (eds.) Proceedings of the corpus linguistics 2003 UCREL technical papers, Vol. 16, part 1, special issue (2003), p. 14-21.

BAKER, M. (1993) Corpus linguistics and translation studies: implications and applications. In: Baker, M.; Francis, G.; TogniniBonelli, E. (eds.) Text and technology. In honour of John Sinclair. Amsterdam and Philadelphia, John Benjamins.

- (1995) Corpora in translation studies: an overview and some suggestions for future research. In: Target 7(2), p. 223-43.

. (1996a) Corpus-based translation studies: the challenges that

lie ahead. In: Somers, H. (ed.) Terminology, lsp and translation studies in language engineering: in honour of Juan C. Sager. Amsterdam and Philadelphia, John Benjamins, p. 175-86.

(1996b) Linguistics and cultural studies: complementary or competing paradigms in translation studies?. In: Lauer, A.; Gerzymisch-Arbogast, H.; Haller, J. and Steiner, E. (eds.) Übersetzungswissenschaft im Umbruch: Festschrift für Wolfram Wilss. Tübingen, Gunter Narr, p. 9-19.

TRADTERM, 10, 2004, p. 29-57 
. (1998) Réexplorer la Langue de la traduction: une approche par corpus. In: Laviosa, S. (ed.). p. 480-485.

. (1999) The role of corpora in investigating the linguistic behaviour of professional translators. International journal of corpus linguistics, $4(2)$, p. 281-98.

. (2000) Towards a methodology for investigating the style of a literary translator. In: Target 12(2), p. 241-66.

- (2002) Corpus-based studies within the larger context of translation studies. In: Génesis: revista cientifica do ISAI 2, p. 7-16.

AUBERT, F. H. and TAGNIN, S.E.O. (2003) A corpus of sworn translations - for linguistic and historical research. In: Archer, D.; Rayson, P.; Wilson, A. and McEnery T. (eds.), Proceedings of the corpus linguistics 2003 ucrel technical papers, vol. 16, part 1, special issue (2003), p. 54-61.

BASSNETT, S. (2001) The translation turn in cultural studies. In: Petrilli, S. (ed.) Lo stesso altro, special issue of Athanor XII(4), p. 151-64.

BASSNETT, S. and LEFEVERE, A. (1998) Constructing cultures. Essays on literary translation. Clevedon, Multilingual Matters.

BOWKER, L. (1998) Using specialized monolingual native-language corpora as a translation resource: A pilot study. In Laviosa, S. (ed.), p. 631-51.

(2000) A corpus-based approach to evaluating student translations. Special issue The translator, edited by C. Maier Evaluation and Translation 6(2), p. 183-210.

BRISSET, A. (1990) Sociocritique de la traduction: théâtre et altérité au Québec, 1968-1988. Longueuil, Canada, Le Préambule.

. (1996) A sociocritique of translation: theatre and alterity in Quebec, 1968-1988, trans. Rosalind Gill and Roger Gannon. Toronto, University of Toronto Press.

BURNETT, S. (1999) A corpus-based study of translational english, MSc. Dissertation. Manchester, Centre for Translation and Intercultural Studies, UMIST.

CAMARGO, D.C. de (2001) Corpus-based translation research on legal, technical and corporate texts. In: Across Languages and Cultures 2(1), p. 113-25.

CAREY, F. H. (1844) The vision of hell, purgatory and paradise of Dante Alighieri. London, George Bell \& Sons.

CHAFE, W.L.; DUBOIS, J.W. and THOMPSON, S.A. (1991) Towards a new corpus of spoken american english. In: Aijmer, K. and Altenberg,

TRADTERM, 10, 2004, p. 29-57 
B. (eds.) English corpus linguistics in honor of Jan Svartvik. London and New York, Longman, p. 64-82.

CHESTERMAN, A. (1998) Causes, translations, effects. In: Target 12(1), p. 200-230.

(2000) A causal model for translation studies. In: Olohan, M. (ed.), p. 15-27.

CHESTERMAN, A. and ARROJO, R. (2000) Shared grounds in translation studies. Target 12(1), p. 151-60.

FRAWLEY, W. (1984) Prolegomenon to a theory of translation. In: Frawley, W. (ed.) Translation: literary, linguistic and philosophical perspectives. London and Toronto, Associated University Presses.

GAVIOLI, L. (1997) Corpora di testi elettronici e concordanze: un'esperienza in un corso universitario per traduttori. In: Atti del simposio su didattica e informatica. Livorno 9-11 Ottobre 1997. Livorno, Accademia Navale, p. 131-4.

(1999) Corpora and the concordancer in learning ESP. An experiment in a course for intepreters and translators. In: Azzaro, G. and Ulrych, M. (eds.) Anglistica e ... i metodi e percorsi comparatistici nelle lingue, culture e letterature di origine europea, vol. II Transiti linguistici e culturali. Trieste, EUT, p. 331-44.

GAVIOLI, L. and ZANETTIN, F. (1997) Comparable corpora and translation: a pedagogic perspective. In: Aston, G.; Gavioli, L. and Zanettin, F. (eds.) Corpus use and learning to translate. On line at: http://www.sslmit.unibo.it/cultpaps/.

GELLERSTAM, M. (1986) Translationese in swedish novels translated from English. In: Wollin, L. and Lindquist, H. (eds.) Translation studies in Scandinavia. Proceedings from the Scandinavian Symposium on Translation Theory (SSOTT) II Lund 14-15 June 1985, Lund Studies in English 75. Lund, CWK Gleerup, p. 88-95.

HALVERSON, S. (1998) Translation studies and representative corpora: establishing links between translation corpora, theoretical/descriptive categories and the conception of the object of study. In: Laviosa, S. (ed.), p. 494-514.

HATIM, B. (1999) The cultural and the textual in the way translation studies has evolved. Paper presented at the University of Salford, UK, ESRI Research Seminars 24 March.

HATIM, B. and Mason, I. (1990) Discourse and the translator. London, Longman.

TradTerm, 10, 2004, p. 29-57 

. (1997) The translator as communicator. London and New York, Routledge.

GODAYOL I NOGUÉ, P. (2000) Espais de frontera génere i traducció. Vic, Eumo Editorial.

. (2002) Spazi di frontiera. Genere e traduzione, trans. Annarita Taronna. Bari, Palomar.

JOHANSSON, S. (1998) On the role of corpora in cross-linguistic research. In: Johansson, S. and Oksefjell, S. (eds.) Corpora and cross-linguistic research: theory, method, and case studies. Amsterdam and Atlanta, Rodopi, p. 3-24.

JOHANSSON, S. and HOFLAND, K. (1994) Towards an English-Norwegian Parallel Corpus. In: Fries, U.; Tottie, G. and Schneider, P. (eds.) Creating and using English language corpora, Papers from the Fourteenth International Conference on English Language Research on Computerized Corpora, Zurich May 19-23 1993. Amsterdam and Atlanta, Rodopi, p. 25-37.

JOHNS, T.F. (1997a) Multiconcord: the lingua multilingual parallel concordancer for Windows. On line at: http://web.bham.ac.uk/johnsf/. . (1997b) Reciprocal learning: an application of parallel concordancing, paper presented at Corpus Use and Learning to Translate, Bertinoro, Italy, 14-15 November.

KEMPPANEN, H. (2000) Looking for evaluative keywords in authentic and translated Finnish: corpus research on Finnish history texts, paper presented at Research Models in Translation Studies, UMIST and UCL, Manchester 28-30 April.

. (2001) Ideology in translation - challenging universals?, paper presented at Translation universals - do they exist?, Savonlinna School of Translation, University of Joensuu, Finland, 19-20 October.

KENNY, D. (1998) Corpora in translation studies. In: Baker, M. (ed.) Routledge encyclopedia of translation studies. London and New York, Routledge, p. 50-3.

. (1999) Norms and creativity: lexis in translated text, $\mathrm{PhD}$. Thesis. Manchester, Department of Language Engineering, UMIST.

KRUGER, A. (2000) Lexical cohesion and register variation in translation: the Merchant of Venice in Afrikaans, D. Litt et Phil. Thesis. Pretoria, University of South Africa.

LAVIOSA, S. (ed.) (1998) L'approche basèe sur le corpus/The corpus-based approach, special issue Meta 43(4). Montréal, Les Presses de L’Université de Montréal.

TRadTerm, 10, 2004, p. 29-57 
. (2002a) Corpus-based translation studies. Theory, findings, applications. Amsterdam and Atlanta, Rodopi.

. $(2002 \mathrm{~b})$ Europe in the making in translational and nontranslational English. In: Harvey, K. (ed.) CTIS Occasional Papers, Vol. 2. Manchester, CTIS, UMIST, p. 85-95.

(2004) When Italians talk 'business' they mean it, this issue.

LAVIOSA-BRAITHWAITE, S. (1996) The English comparable corpus (ECC): a resource and a methodology for the empirical study of translation, PhD. Thesis. Manchester, Department of Language Engineering, UMIST.

LEECH, J. (1992) Corpora and theories of linguistic performance. In: Svartvik, J. (ed.) Directions in corpus linguistics, Proceedings of Nobel Symposium 82, Stockholm, 4-8 August 1991, Trends in linguistics: studies and monographs, 65. Berlin and New York, Mouton de Gruyter, p. 105-22.

LINDQUIST, H. (1989) English adverbials in translation: a corpus study of swedish renderings. Lund studies in english 80. Lund, Lund University Press.

LITTAU, K. (1995) Pandora's tongues, paper presented at the EST Congress in Prague, September 1995.

LONGFELLOW, H. W. (1895) The divine comedy of dante Alighieri. Houghton, Mifflin.

MALHERBE, D.F. (1949) Die koopman van Venesië. Johannesburg, Afrikaanse Pers-Boekhandel.

MALMKJÆER, K. (1998) Love thy neighbour: will parallel corpora endear linguists to translators?. In: Laviosa, S. (ed.), p. 534-41.

MANDELBAUM, A. (1980) Inferno: the divine comedy of Dante Alighieri. London, Bantam Doubleday.

MAURANEN, A. (2000) Strange strings in translated language. A study on corpora. In: Olohan, M. (ed.), p. 119-41.

MAY, R. (1994) The translator in the text: on reading russian literature in English. Evanston, Illinois, Northwestern University Press.

MUNDAY, J. (1997) Systems in translation: a computer-assisted systemic approach to the analysis of the translation of Garcia Márquez, PhD. Thesis. Bradford, Department of Modern Languages, University of Bradford.

OLOHAN, M. (ed.) (2000) Intercultural faultlines. Research models in translation studies 1: Textual and cognitive aspects. Manchester, St. Jerome.

TradTerm, 10, 2004, p. 29-57 
OLOHAN, M. and Baker, M. (2000) Reporting that in translated english: evidence for subconscious processes of explicitation?. Across languages and cultures 1(2), p. 141-58.

ØVERÅS, L. (1998) In search of the third code: an investigation of norms in literary translation. In: Laviosa, S. (ed.), p. 571-88.

POTGIETER, T. (1991) Die sakeman van Venesië, unpublished manuscript, PACT, the translator.

SAID, E. (1991) The world, the text and the critic. London, Vintage.

SAYERS, D.L. (1949) Wonders of the world: The divine comedy: hell. Harmondsworth, Penguin.

SCOTT, M.N. (1998) Normalisation and readers' expectation: a study of literary translation with reference to Lispector's 'A hora da estrela', $\mathrm{PhD}$. thesis. Liverpool, AELSU, University of Liverpool.

SHLESINGER, M. (1998) Corpus-based interpreting studies as an offshoot of corpus-based translation studies. In: Laviosa, S. (ed.), p. 486-93.

SINCLAIR, J. (1991) Corpus concordance collocation. Oxford, Oxford University Press.

STEWART, D. (2000) Conventionality, creativity, and translated text: the implications of electronic corpora in translation. In: Olohan, M. (ed.), p. 73-91.

TAGNIN, S.E.O. (2003) COMET - a multilingual corpus for teaching and translation. Lewandowska, B. (ed.) PALC 2001 - practical applications in language corpora. Berlin, Peter Lang, p. 535-40.

TIRKKONEN-CONDIT, E. (2000) In search of translation universals: nonequivalence or 'unique' items in a corpus text, paper presented at Research Models in Translation Studies. UMIST and UCL, Manchester 28-30 April.

TOGNINI-BONELLI, E. and MANCA, E. (2004). Welcoming children, pets and guests: a problem of non-equivalence in the languages of 'agriturismo' and 'farmhouse holidays', this issue.

TOURY, G. (1980) In search of a theory of translation. Tel Aviv, The Porter Institute for Poetics and Semiotics, Tel Aviv University. . (1995) Descriptive translation studies and beyond. Amsterdam and Philadelphia, John Benjamins.

TYMOCZKO, M. (1998) Computerized corpora and the future of translation studies. In: Laviosa, S. (ed.), p. 652-60.

VENUTI, L. (2000) The translation studies reader. London and New York, Routledge.

TRadTerm, 10, 2004, p. 29-57 
WEISSBROD, R. (1992) Explicitation in translations of prose-fiction from English to Hebrew as a function norm. Multilingua II(2), p. 153-71. ZANETTIN, F. (1998) Bilingual comparable corpora and the training of translators, in Laviosa, S. (ed.), p. 616-30. (2002) CEXI: designing an english Italian translational corpus.

Language and Computers 42(1), p. 329-43.

TradTerm, 10, 2004, p. 29-57 